\title{
URGENSI BAHASA ARAB
}

\author{
Muhammad Arif Lili \\ Sekolah Tinggi Agama Islam Negeri (STAIN) Sorong, Papua Barat, Indonesia \\ Email:ariefmuh69@gmail.com
}

\begin{abstract}
ABSTRAK
Bahasa Arab adalah salah satu alat komunikasi yang dengannya kita sebagai manusia dapat berinteraksi satu sama lain. Selain itu, bahasa Arab memiliki keistimewaan tersendiri daripada bahasa bahasa yang lain yaitu bahasa utama umat islam, sebagai bahasa Al-Quran dan Hadist, dan bahasa surga yang In Sya Allah kita nanti berada didalamnya.
\end{abstract}

\section{PENDAHULUAN}

Bahasa merupakan suatu kebutuhan dasar dan penting bagi manusia, karena bahasa adalah media penyampai ide, gagasan, dan pikiran manusia dalam bentuk ucapan atau tulisan dengan maksud agar dipahami oleh orang lain. Seiring dengan perjalanan waktu kehidupan manusia ragam bahasa pun semakin banyak, diantaranya bahasa Arab, Inggris, China, Spanyol, Korea, Jepang, dan lain-lain.

Bahasa ini digunakan secara resmi oleh kurang lebih 20 negara. Alasan lainnya karena bahasa Arab adalah bahasa kitab suci dan tuntunan agama umat Islam sedunia, maka tentu saja ia merupakan bahasa yang paling besar signifikansinya bagi milyaran muslim sedunia, baik yang berkebangsaan Arab maupun bukan Arab.

Bahasa Arab adalah bahasa Agama Islam dan bahasa al-Qur'an, seseorang tidak akan dapat memahami kitab dan sunnah dengan pemahaman yang benar dan selamat (dari penyelewengan) kecuali dengan bahasa Arab. Menyepelekan dan menggampangkan Bahasa Arab akan mengakibatkan lemah dalam memahami agama 
serta jahil (bodoh) terhadap permasalahan agama.

Sungguh sangat ironis dan menyedihkan, sekolah-sekolah dinegeri kita, bahasa Arab tersisihkan oleh bahasa-bahasa lain, padahal mayoritas penduduk negeri kita adalah beragama Islam, sehingga keadaan kaum muslimin dinegeri ini jauh dari tuntunan Allah ta'ala dan Rasul-Nya.

\section{PENTINGNYA BAHASA ARAB}

Betapa pentingnya bahasa Arab bagi manusia kiranya tidak perlu diragukan lagi. Hal itu dapat dibuktikan dengan menunjukan pemakaian bahasa dalam segi sehari-hari, lebih-lebih bahasa arab yang selalu kita pakai dalam melaksanankan ibadah, seperti halnya sholat jika kita mengetaui arti dari apa yang kita ucapkan juga akan menambah kekhususan dalam sholat, haji jika kita paham dengan bahasa arab kita juga akan mudah berkomunikasi dengan orang Arab ketika berkomunikasi dengan orang arab ketika melaksanakan ibadah haji.

Selain itu dalam bahasa arab memiliki tata bahasa yang sangat sulit sehingga banyak pakar ilmuan membahas tetang tata bahasa arab yang bertujuan tuntuk lebih memudahkan kita dalam mendalami pemahaman Alqur'an dan hadis yang kesemuanya memakai bahasa Arab, Al-Qur'an dan hadis merupakan sumber hukum yang paten sehingga kita dituntut untuk memami bahasa Arab. Seperti sabda nabi :

قال رسول الله صلى الله عليه وسلم:تركت فيكم شيئين لن تضلوا ما تمسكتم بهما كتاب الله و سنة رسوله

" Aku tinggalkan untukmu semua, dua perkara jika kalian semua berpegang teguh dengannya maka kamu semua tidak akan sesat yaitu Al-Qur'an dan Hadits.

Dengan sederhana, bahasa dapat diartikan sebagai alat untuk menyampaikan sesuatu yang terlintas di dalam hati. Akan tetapi lebih jauh bahasa bahasa ialah alat untuk beriteraksi atau alat untuk berkomunikasi, dalam arti alat untuk menyampaikan pikiran, gagasan, konsep atau perasaan. Di dalam studi sosiolinguistik, bahasa diartikan sebagai sebuah sistem lambang yang berupa bunyi, produktif, dinamis, beragam dan manusiawi. 
Bahasa ialah sebuah sistem, itu artinya, bahasa dibentuk oleh sejumlah komponen yang berpola dengan tetap dan dapat dikaidahkan. Sistem bahasa berupa lambang-lambang bunyi, setiap lambang bahasa akan melambangkan sesuatu yang disebut makna atau konsep. Karena setiap lambang bunyi itu mepunyai atau menyatakan suatu konsep atau makna, maka dapat disimpulkan bahwa setiap suatu ujaran bahasa mempunyai arti.

Bahasa merupakan sarana untuk mempermudah terjadinya sebuah interaksi di antara manusia. Allah menciptakan manusia dengan perbedaan suku, ras, bahasa dan keanekaragaman yang lain. Karena perbedaan tersebut, kita harus saling mengenal dengan yang lain. Bahasa Internasional kita adalah bahasa Indonesia, dari Sabang hingga Merauke terdapat ribuan ragam bahasa, namun untuk mempermudah komunikasi dengan suku yang lain, dengan menggunakan bahasa Indonesia. Ada beberapa fungsi bahasa yakni:

1. Fungsi Personal atau Pribadi

Artinya, si penutur menyatakan sikap terhadap apa yang dituturkannya. Si penutur tidak hanya mengungkapkan emosi lewat bahasa, namun juga memperlihatkan emosi itu sewaktu menyampaikan tuturannya.

2. Fungsi Direktif

Dilihat dari sudut pendengar atau lawan bicara, bahasa berfungsi secara direktif, yakni mengatur tingkah laku pendengar.

3. Fungsi Fatik

Jika dilihat segi kontak antara penutur dan pendengar, maka bahasa bersifat fatik. Itu artinya bahasa berfungsi menjalin hubungan, memelihara, memperlihatkan perasaan bersahabat atau solidaritas sosial.

4. Fungsi Referensial

Fungsi referensial ini yang melahirkan paham tradisional bahwa bahasa itu ialah alat untuk menyatakan pikiran, untuk menyatakan bagaimana si penutur tentang dunia di sekelilingnya. 
5. Fungsi Metalingual atau Metalinguistik

Fungsinya di sini bahasa digunakan untuk membicarakan atau menjelaskan bahasa. Hal ini dapat dilihat dalam proses pembelajaran bahasa di mana kaidah-kaidah bahasa dijelaskan dengan bahasa.

6. Fungsi Imajinatif

Fungsi imajinasi ini biasanya berupa karya seni seperti puisi, cerita, dongeng dan sebagainya yang digunakan untuk kesenangan penutur atau para pendengarnya.

Tak bisa dipungkiri bahwa bahasa Inggris adalah bahasa internasional, yang dipakai oleh para turis untuk berkomunikasi ketika sedang berwisata/berkunjung kenegara lain.

Bahasa Inggris merupakan bahasa Internasional, tapi masih ada lagi bahasa yang mendunia, yakni bahasa Arab. Hampir dalam satu abad yang lalu, bahas Arab merupakan bahasa yang terpenting dalam kehidupan, mencuat melebihi bahasa yang lain. Karena pada saat itu kehidupan islam atau negara islam sangat memprioritaskan bahasa Arab tersebut.

Mungkin di zaman sekarang orang banyak berburu atau ingin bisa menguasai bahasa Inggris. Tetapi bahasa Arab juga harus diprioritaskan, karena:

1) Bahasa Arab adalah bahasa Al-Qur'an

Di seluruh dunia mushaf Al-Qur'an pasti menggunakan bahasa Arab, hanya saja diterjemahkan ke dalam berbagai bahasa agar mudah dipahami.

2) Banyak sejarah-sejarah menggunakan bahasa Arab, khususnya sejarah islam dan peradabannya.

3) Bahasa Arab merupakan bahasa akhirat, kita mati dan berada di dalam kubur bersama malaikat, kita ditanyai juga dengan bahasa Arab "man rabbuka" atau "siapa tuhanmu?"

Tapi, sesuai denga fakta yang ada, semakin berkembangnya zaman ini semakin 
sedikit pula orang yang peduli yang mau mendalami bahasa Arab. Hanya di pesantrenpesantren ataupun sekolah yang berbasis islam saja yang mau menjadikan bahasa Arab sebagai mata pembelajaran. Padahal kita sudah tau bahwa belajar bahasa Arab juga pentinguntuk kedepannya. Banyak kita jumpai buku-buku mengenai kesehatan, praktikum, pemdalaman agama juga menggunakan bahasa Arab.

Jadi, bahas Arab sangatlah penting bagi kehidupan kita, karena islam saat islam sudah tegak kembali, bahasa Arab akan menjadi prioritas dalam kehidupan. Karen asesungguhnya bahasa itu mudah untuk dipelajari jika terdapat kemauan dalam diri ini

Pada zaman sekarang ini, tidak hanya Bahasa Inggris yang dianggap penting dalam pembelajaran, tetapi juga bahasa Arab juga teramat penting untuk dipelajari. Bahkan sejak zaman dahulu, para pejuang Islam di Indonesia pun, khususnya di tanah jawa tidak menganjurkan untuk selalu mempelajari bahasa Inggris dalam keseharian masyarakat. Mereka justru lebih mengutamakan bahasa Arab.

Alasan terpenting mempelajari bahasa Arab, tentu saja bagi yang berbahasa ibu selain bahasa Arab, adalah karena al-Qur'an diturunkan dalam bahasa Arab. Allah Subhanahu wa Ta'ala telah menetapkan bahwa firman-firmanNya yang terakhir diturunkan dalam bahasa Arab. Untuk memahami rahasia diturunkannya al-Qur'an dalam bahasa Arab sudah sepantasnya kita merujuk kepada al-Qur'an itu sendiri. Ayatayat yang membicarakan masalah ini antara lain :

1) Dalam surat yusuf ayat 02 yang berbunyi : Artinya :"Sesungguhnya kami menurunkannya berupa Al Quran dengan berbahasa Arab, agar kamu memahaminya". (Q.S. Yusuf: 02) Diterangkan dalam kitab tafsir Ibnu Katsir bahwa maksud ayat ini adalah bahasa Arab merupakan bahasa yang memiliki arti yang paling mengesankan/elok, jelas, dalam, dan penuh perasaan yang timbul dipikiran seseorang. Oleh karena itu, Kitab yang paling mulia sudah sepantasnya diwahyukan dalam bahasa yang paling mulia, kepada Nabi dan Rosul termulia, melalui perantara Malaikat termulia, di atas tanah paling mulia di permukaan bumi, dan permulaan pewahyuannya adalah di bulan termulia, yaitu bulan Ramadlan. Oleh karena itu, Al-Qur'an merupakan Kitab yang sempurna dari segala aspek. 
2) Dalam surat Ad-Dukhaan ayat 58 yang Artinya: "Sesungguhnya kami mudahkan Al Quran itu dengan bahasamu supaya mereka mendapat pelajaran". (Q.S. AdDukhaan: 58) Imam Ibnu Katsier menafsirkan ayat ini bahwa Allah telah mewahyukan Al-Qur'an secara mudah, terang, dan je;as, dalam bahasa Arab yang merupakan bahasa paling elok, jelas, dan indah dibandingkan seluruh bahasa yang ada.

Dalam Al-Quran juga bertuliskan Bahasa Arab, dalam kitab kitab ijma' maupun Qiyas, juga bertulis dengn aksara Arab, tentu saja dengan menggunakan bahasa Arab. Memang bahasa Arab sangat penting sejak zaman nabi Adam sampai sekarang.

Mengapa saya kaitkan masalah pentingnya bahasa Arab dengan masalah yang berbau Agama Islam. Memang. Kita hidup ini tujuan utama adalah mencari ridho Allah yang jalan satu satunya hanyalah memperbaiki agama Islam kita dan melanggengkannya sampai akhir nanti. Dalam proses perbaikan tersebut, tentu beragam amalan yang harus kita tempuh, yang harus kita laksanakan, sebagai syarat untuk mendapatkan ridla-Nya. Apabila sudah demikian, kita adalah penghuni surga nantinya. Amiinn....

Salah satu amalan untuk memperbaiki Islam kita yaitu dimulai dengan mempelajari bahasa Arab sampai bisa. Minimal kita tahu makna dari kalimat kalimat yang bertuliskan Arab, kita tidak diwajibkan untuk lancer dalam berbahasa Arab. Karena, kita sebagai umat Islam, setiap harinya harus mengamalkan sesuai dengan yang dikandung Al-Quran.

Sementara Al-Quran berbahasa Arab. Memang, ulama telah menjelaskan bahwa kita sebagai orang awam tidak mampu untuk mencerna makna dari kadungan Alquran secara mentah mentah walaupun kita mahir dalam berbahasa Arab. Maka dari itu di buatllah ljma dan Qiyas untuk kita gunakan sebagai pedoman sehari hari. Tapi apalah daya untuk mempelajari ljma dan Qiyas, kalau kita tidak bisa berbahsa Arab. Sementara ljma dan Qiyas pun juga berbahasa Arab.

Apakah Kita harus bergantung terus dengan Al-Quran terjemahan. Apakh kita harus 
bergantung terus dengan Tutorial agama Islam dengan bahasa Indonesia. Ingat, kandungan yang dimuat dalam tuntunan Islam yang berbahasa Indonesia sangatlah minimalis. Semisal, kita mempunyai buku tuntunan tata cara Sholat. Alangkah baiknya kita mempunyai kitab Fasholatan yang isinya merupakn ringkasan dari Ilmu Fiqih secara mendasar. Itupun juga berbahasa Arab.

Dan untuk mempelajari bahasa Arab secara aktif dalam berkomunikasi, itu semisal digunakan untuk berkomunikasi internasional. Misal, dalam acara Haji ke Makkah, kita juga membutuhkan kelancaran dalm berbahasa Arab. Apa tidak lucu kalau kita menggunakan bahasa Inggris untuk berbicara dengan warga local Arab Saudi, apalagi menggunakan bahasa Indonesia, mereka malah tidak faham.Selain itu, bahasa Arab merupakan bahasa yang pertama kali diturunkan untuk nenek moyang kita, nabi Adam dan Hawa.

Imam Syafi'i berkata: "Manusia tidak menjadi bodoh dan selalu berselisih paham kecuali lantaran mereka meninggalkan bahasa Arab, dan lebih mengutamakan konsep Aristoteles".

Itulah ungkapan Imam Syafi'i buat umat, agar kita jangan memarginalkan bahasa kebanggaan umat Islam. Seandainya sang imam menyaksikan kondisi umat sekarang ini terhadap bahasa Arab, tentulah keprihatian beliau akan semakin memuncak.

Bahasa Arab berbeda dengan bahasa-bahasa lain yang menjadi alat komunikasi di kalangan umat manusia. Ragam keunggulan bahasa Arab begitu banyak. Idealnya, umat Islam mencurahkan perhatiannya terhadap bahasa ini. Baik dengan mempelajarinya untuk diri mereka sendiri ataupun memfasilitasi dan mengarahkan anak-anak untuk tujuan tersebut.

Di masa lampau, bahasa Arab sangat mendapatkan tempat di hati kaum muslimin. Ulama dan bahkan para khalifah tidak melihatnya dengan sebelah mata. Fashahah (kebenaran dalam berbahasa) dan ketajaman lidah dalam berbahasa menjadi salah satu indikasi keberhasilan orang tua dalam mendidik anaknya saat masa kecil.

Redupnya pehatian terhadap bahasa Arab nampak ketika penyebaran Islam sudah memasuki negara-negara 'ajam (non Arab). Antar ras saling berinteraksi dan 
bersatu di bawah payung Islam. Kesalahan ejaan semakin dominan dalam perbincangan. Apalagi bila dicermati realita umat Islam sekarang pada umumnya, banyak yang menganaktirikan bahasa Arab. Yang cukup memprihatinkan ternyata, para orang tua kurang mendorong anak-anaknya agar dapat menekuni bahasa Arab.

Pertama:

Keutamaan bahasa Arab amatlah jelas karena bahasa Arab adalah bahasa AlQur'an Al-Karim. Cukup alasan inilah yang jadi alasan besar kenapa kita harus mempelajari bahasa Arab. Keistimewaan bahasa Arab disebutkan dalam Al-Qur'an lebih dari sepuluh tempat, di antaranya pada ayat,

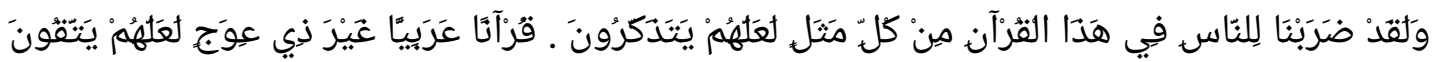

"Sesungguhnya telah Kami buatkan bagi manusia dalam Al Quran ini setiap macam perumpamaan supaya mereka dapat pelajaran. (Ialah) Al Quran dalam bahasa Arab yang tidak ada kebengkokan (di dalamnya) supaya mereka bertakwa." (QS. AzZumar: 27-28)

Syaikhul Islam Ibnu Taimiyah rahimahullah berkata,

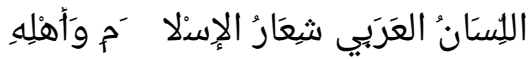

"Bahasa Arab adalah syi'ar Islam dan syi'ar kaum muslimin." Disebutkan dalam Iqtidha' Shirath Al-Mustaqim.

Kedua:

Dengan mempelajari bahasa Arab lebih mudah dalam menghafalkan, memahami, mengajarkan dan mengamalkan isi Al-Qur'an. Dengan modal bahasa Arab akan mudah pula dalam memahami hadits-hadits Nabi shallallahu 'alaihi wa sallam, menghafalkan, menjelaskan serta mengamalkannya.

Ketiga:

Orang yang paham bahasa Arab, terutama paham kaedah-kaedah dalam ilmu nahwu akan semakin mudah memahami Islam daripada yang tidak mempelajarinya sama sekali. Apalagi jika tugas seseorang sebagai penyampai dakwah, menjadi seorang da'i, kyai atau ustadz, tentu lebih urgent lagi mempelajarinya agar mudah memberikan 
pemahaman agama yang benar pada orang banyak.

Keempat:

Orang yang paham bahasa Arab akan mudah menggali ilmu dari ulama secara langsung atau membaca berbagai karya ulama yang sudah banyak tersebar hingga saat ini. Sedangkan yang tidak paham bahasa Arab hanya bisa mengandalkan kitab terjemahan dan itu sifatnya terbatas.

Kelima:

Bahasa Arab itu bahasa yang lembut dan lebih mengenakkan hati, serta menentramkan jiwa.

Ibnu Katsir saat menjelaskan surat Yusuf ayat kedua menyatakan,

لأن لغة العرب آفصح اللغات وأبينها وأوسعها، وآكثرها تأدية للمعاني التي تقوم بالنفوس

"Karena bahasa Arab adalah bahasa yang paling fasih, paling jelas, paling luas (kosakatanya), dan paling banyak mengandung makna yang menentramkan jiwa." Keenam:

Bahasa Arab adalah bahasa yang paling mulia.

Ibnu Katsir rahimahullah juga menyatakan,

فلهذا آنزل آشرف الكتب بأشرف اللغات، على أشرف الرسل، بسفارة أشرف الملائكة، وكان ذلك في آشرف بقاع الأ

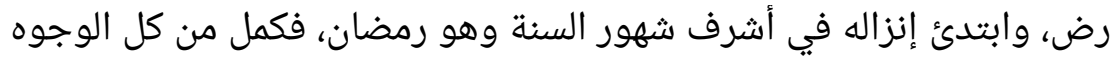

"Karena Al-Qur'an adalah kitab yang paling mulia, diturunkan dengan bahasa yang paling mulia, diajarkan pada Rasul yang paling mulia, disampaikan oleh malaikat yang paling mulia, diturunkan di tempat yang paling mulia di muka bumi, diturunkan pula di bulan yang mulia yaitu bulan Ramadhan. Dari berbagai sisi itu, kita bisa menilai bagaimanakah mulianya kitab suci Al-Qur'an".

Oleh karena itu Allah nyatakan tentang bahasa Arab,

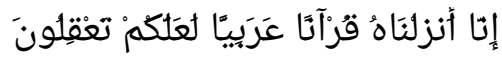

"Sesungguhnya Kami menurunkannya berupa Al Quran dengan berbahasa Arab, agar kamu memahaminya." (QS. Yusuf: 2) 
Ketujuh:

Bahasa Arab adalah bahasa yang lurus, mudah dipahami dan mudah digunakan sebagai hukum bagi manusia.

Allah menyatakan sendiri,

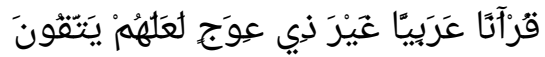

"(Ialah) Al-Qur'an dalam bahasa Arab yang tidak ada kebengkokan (di dalamnya) supaya mereka bertakwa." (QS. Az-Zumar: 28)

Dalam ayat lain disebutkan,

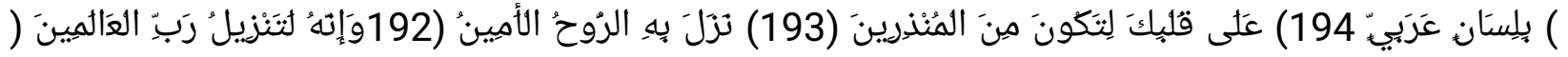
)

“Dan sesungguhnya Al Quran ini benar-benar diturunkan oleh Tuhan semesta alam, dia dibawa turun oleh Ar-Ruh Al-Amin (Jibril), ke dalam hatimu (Muhammad) agar kamu menjadi salah seorang di antara orang-orang yang memberi peringatan, dengan bahasa Arab yang jelas." (QS. Asy-Syu'ara: 192-195). Sebagaimana disebutkan dalam Zaad AlMasiir karya Ibnul Jauzi, Al-Qur'an diturunkan dengan bahasa Arab yaitu bahasanya orang Quraisy yang setiap orang mudah memahaminya.

Juga dalam ayat lain disebutkan,

وَكدَلِكَ أَنْزَلنَاهُ حُكمًَا عَرَبِيًا

"Dan demikianlah, Kami telah menurunkan Al Quran itu sebagai peraturan (yang benar) dalam bahasa Arab." (QS. Ar-Ra'du: 37). Disebutkan dalam Tafsir Al-Jalalain, bahasa Arab digunakan sebagai hukum di tengah-tengah manusia. Dalam Zaad Al-Masiir disebutkan bahwa bahasa Arab bisa digunakan untuk menerangkan hukum-hukum yang wajib.

Beberapa keistimewaan bahasa arab antara lain adalah:

1) Bahasa Arab adalah bahasa Al Quran. Allah berfirman: 


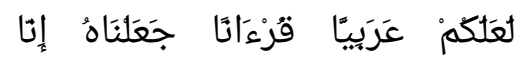

تعُقِلونَ

"Sesungguhnya Kami telah menjadikan Al Quran dalam bahasa Arab, supaya kalian memahaminya".

2) Bahasa Arab adalah bahasa Nabi Muhammad dan bahasa verbal para sahabat. Hadits_hadits Nabi yang sampai kepada kita dengan berbahasa Arab. Demikian juga kitab-kitab fikih, tertulis dengan bahasa ini. Oleh karena itu, penguasaan bahasa Arab menjadi pintu gerbang dalam memahaminya.

3) Susunan kata bahasa Arab tidak banyak. Kebanyakan terdiri atas susunan tiga huruf saja. Ini akan mempermudah pemahaman dan pengucapannya.

4) Indahnya kosa kata Arab. Orang yang mencermati ungkapan dan kalimat dalam bahasa Arab, ia akan merasakan sebuah ungkapan yang indah dan gamblang, tersusun dengan kata-kata yang ringkas dan padat.

Pentingnya bahasa arab juga dapat Dilihat dari bagaimana perhatian para para para salaf terhadap bahasa arab sebagaimana ketika Umar bin Khaththab pernah menulis surat kepada Abu Musa yang berisi pesan: "Amma ba'du, pahamilah sunnah dan pelajarilah bahasa Arab".

Pada kesempatan lain, beliau mengatakan: "Semoga Allah merahmati orang yang meluruskan lisannya (dengan belajar bahasa Arab)".

Pada kesempatan lain lagi, beliau menyatakan: "Pelajarilah agama, dan ibadah yang baik, serta mendalami bahasa Arab".

Beliau juga mengatakan: "Pelajarilah bahasa Arab, sebab ia mampu menguatkan akal dan menambah kehormatan".

Para ulama tidak mengecilkan arti bahasa Arab. Mereka tetap memberikan perhatian yang besar dalam menekuninya, layaknya ilmu syar'i lainnya. Sebab bahasa Arab adalah perangkat dan sarana untuk memahami ilmu syariat.

Imam Syafi'i pernah berkata: "Aku tinggal di pedesaan selama dua puluh tahun. Aku 
pelajari syair-syair dan bahasa mereka. Aku menghafal Al Qur'an. Tidak pernah ada satu kata yang terlewatkan olehku, kecuali aku memahami maknanya".

Imam Syafi'i telah mencapai puncak dalam penguasaan bahasa Arab, sehingga dijuluki sebagai orang Quraisy yang paling fasih pada masanya. Dia termasuk yang menjadi rujukan bahasa Arab.

Ibnul Qayyim juga dikenal memiliki perhatian yang kuat terhadap bahasa Arab. Beliau belajar kepada Ibnul Fathi Al Ba'li kitab Al Mulakhkhash karya Abul Baqa', Al Jurjaniyah, Alfiyah Ibni Malik, Al Kafiyah Asy Syafiah dan At Tashil. Beliau juga belajar dari Ali bin Majd At Tusi.

Syaikhul Islam Ibnu Taimiyah rahimahullah berkata, "Bahasa arab itu termasuk bagian dari agama, sedangkan mempelajarinya adalah wajib, karena memahami AlQuran dan As-Sunnah itu wajib. Tidaklah seseorang bisa memahami keduanya kecuali dengan bahasa arab. Dan tidaklah kewajiban itu sempurna kecuali dengannya (mempalajari bahasa Arab), maka ia (mempelajari bahasa arab) menjadi wajib. Mempelajari bahasa arab, diantaranya ada yang fardhu 'ain, dan adakalanya fardhu kifayah. Dorongan untuk belajar bahasa arab bukan hanya khusus bagi orang-orang di luar negara Arab. Bahkan para salafush sholeh sangat mendorong manusia (bahkan untuk orang Arab itu sendiri) untuk mempelajari bahasa arab.

Umar R.A juga mengingatkan para sahabatnya yang bergaul bersama orang asing untuk tidak melalaikan bahasa Arab. Ia menulis surat kepada Abu Musa al-Asy'ari, "Adapun setelah itu, pelajarilah Sunnah dan pelajarilah bahasa arab, i'rablah al-Qur'an karena dia (al-Qur'an) dari Arab.

Dari Hasan Al-Bashari, beliau pernah ditanya, "Apa pendapat Anda tentang suatu kaum yang belajar bahasa arab?" Maka beliau menjawab, "Mereka adalah orang yang baik, karena mereka mempelajari agama nabi mereka.

Ulama lain yang terkenal memiliki perhatian yang besar terhadap bahasa Arab adalah Imam Syaukani. Ulama ini menimba ilmu nahwu dan sharaf dari tiga ulama sekaligus, yaitu : Sayyid Isma'il bin Al Hasan, Allamah Abdullah bin Ismail An Nahmi, dan Allamah Qasim bin Muhammad Al Khaulani. 
Dan para anak-anak khalifa juga disuruh belajar bahasa arab, selain mengajarkan pada anak-anak dengan ilmu-ilmu agama, mereka juga memberikan jadwal khusus untuk memperdalam bahasa Arab dan sastranya. Motivasi mereka, lantaran mengetahui nilai positif bahasa Arab terhadap gaya ucapan mereka, penanaman budi pekerti, perbaikan ungkapan dalam berbicara, modal dasar mempelajari Islam dari referensinya. Oleh karena itu, ulama bahasa Arab juga memiliki kedudukan dalam pemerintahan dan dekat dengan para khalifah. Para pakar bahasa menjadi guru untuk anak-anak khalifah.

Al Ahmar An Nahwi berkata,"Aku diperintahkan Ar Rasyid untuk mengajarkan sastra Arab kepada anaknya, Muhammad Al Amin. Al Makmun dan Al Amin juga pernah dididik pakar bahasa yang bernama Abul Hasan 'Ali bin Hamzah Al Kisai yang menjadi orang dekat Khalifah. Demikian juga pakar bahasa lain yang dikenal dengan Abu Ishaq Ibrahim bin Muhammad bin As Sari mengajari anak-anak Khalifah Al Mu'tadhid pelajaran bahasa Arab. Juga Abu Qadim Abu Ja'far Muhammad bin Qadim mengajari Al Mu'taz sebelum memegang tampuk pemerintahan".

Daftar pustaka

Adnin Armas, Metodologi Bibel dalam Studi Al-Qur'an, (Jakarta:Gema Insani, 2005) Al-Qattan, Manna. Studi IImu-IImu Al-Qur'an (Surabaya: CV. Rasma Putra) Ar-rum,fahd bin Abdurrahman. dirosat fi ulum al-Qur'an (Titian llahi Press, 1997) Azhar, Arsyad. Bahasa Arab dan Metode Pengajarannya, (Yogyakarta: Pustaka Pelajar) Maurice, Bucaile. the bibel al-Qur'an and science (Jakarta: Bulan Bintang, 1979) Departemen Agama RI, Al-Qur'an dan Terjemahnya, (Jakarta, Tiga Serangkai, 2008) 
Hamid, M Abdul, Dkk, Pembelajaran Bahasa Arab: Pendekatan, Metode, Strategi, Materi dan Media (Malang: UIN Malang Press, 2008)

Asna Andriani. Urgensi Pembelajaran Bahasa Arab dalam Pendidikan Islam. (IAIN Tulungagung, 2015)

Bawani, Imam, Cendikiawan Muslim dalam Perspektif Pendidikan Islam, (Surabaya: Bina Ilmu, 1991)

Chejne, Anwar G. Bahasa Arab dan Peranannya dalam Sejarah, terj. (Aliudin Mahjudin, Jakarta: Pusat Pembinaan dan Pengembangan Bahasa, 1996)

Sahin Abdushshoburl, Al-Arabiyah Lughotul Ulum Wa Taqniyah, (Cairo:Darul i'tshom,1986).

Syamsuddin Hatta, Urgensi Belajar Bahasa Arab, (Surakarta:Ma'had Abu Bakar AsShiddiq, 2010).

Arsyad Azhar, Bahasa Arab dan Metode Pengajarannya, (Yogyakarta: PustakaPelajar, 2004).

1994“Bahasa Arab dan Komunikasi Internasional”. Makalah untuk Seminar Nasional Budaya Arab. IMABA UGM: Yogyakarta

Ali Ahmad Makmur, Tadris Funun Al-Lughatul Al-'Arabiyyah, Daar As-Syawaf Linnasyri Wattauzikh: Mesir, 1999) 